\title{
GMR
}

\section{Efficacy of oral administration of lactic acid bacteria isolated from cocoa in a fermented milk preparation: reduction of colitis in an experimental rat model}

T.F. dos Santos, T.A. Melo, D.S. Santos, R.P. Rezende, J.C.T. Dias and

C.C. Romano

Departamento de Ciências Biológicas, Universidade Estadual de Santa Cruz, Salobrinho, Ilhéus, BA, Brasil

Corresponding author: C.C. Romano

E-mail: romanocc@uol.com.br

Genet. Mol. Res. 15 (3): gmr.15038097

Received November 18, 2015

Accepted March 18, 2016

Published July 29, 2016

DOI http://dx.doi.org/10.4238/gmr.15038097

Copyright (C) 2016 The Authors. This is an open-access article distributed under the terms of the Creative Commons Attribution ShareAlike (CC BY-SA) 4.0 License.

\begin{abstract}
We investigated the probiotic potential of lactic acid bacteria (LAB) obtained from cocoa fermentation using an experimental rat model of colitis. Cocoa beans were collected from fermentation boxes every $12 \mathrm{~h}$ for 5 days to isolate the microorganisms. Strains were isolated by serial dilution and plating on MRS agar. Gram-positive and catalase-negative rods were subjected to DNA extraction, polymerase chain reaction, and sequencing. Ten strains were randomly pooled and used to prepare a fermented milk drink that was used to treat the experimental colitis. A parallel group was treated with a single strain drink. Serum concentrations of cytokines and IgA, total and differential counts of blood leukocytes, and histological appearance were compared with the untreated control colitis group. Eighty strains of LAB were
\end{abstract}


identified as Lactobacillus fermentum (68) and Lactobacillus plantarum (12). The multi-strain LAB pool significantly reduced the total number of leukocytes. There was a significant reduction in the percentage of neutrophils and monocytes compared with the control colitis group. IFN- $\gamma$ concentration was downregulated in animals treated with the LAB pool. IL-10 and IgA increased significantly in the group treated with the strains. Histological analysis showed that the LAB pool reduced the inflammatory infiltrate and restored tissue architecture. The group treated with the single strain LAB drink (L. fermentum) showed no signs of inflammation remission. The results confirm the probiotic action of cocoa-derived LAB in the treatment of experimental colitis. Studies using isogenic models and humans will clarify the mechanisms of immune response modulation in inflammatory bowel disease.

Key words: Lactobacillus; Bowel inflammation; Cocoa fermentation; Potential probiotic

\section{INTRODUCTION}

Probiotics are defined as live microorganisms that, when administered in adequate amounts, confer a health benefit to the host (FAO/WHO, 2002). They are able to prevent or decrease the duration of diarrhea, reduce the tissue damage caused by inflammatory bowel disease (IBD), and mitigate certain clinical conditions such as asthma, cancer, metabolic disorders, and extra-intestinal infections (Lenoir-Wijnkoop et al., 2007; Floch, 2014). Probiotics need to survive gastrointestinal conditions to colonize the intestine, where they represent a barrier to the development of pathogens by competing for adhesion to mucus and epithelial cells, and produce antimicrobial compounds such as bacteriocins and hydrogen peroxide. They also modulate the immune effect by interacting with cellular receptors, enhancing the response to pathogens, or reducing chronic inflammatory responses (Oelschlaeger, 2010; Saez-Lara et al., 2015).

The pathogenesis of IBD, which includes ulcerative colitis and Crohn's disease, has not yet been elucidated and is considered to be multi-factorial. IBD results from an exaggerated and continuous inflammatory response to resident microbiota in individuals with genetic predisposition (Zemljic et al., 2014). A growing body of data indicates that excessive amounts of cytokines, nitric oxide, and chemokines play a role in the development of intestinal damage by disrupting epithelial cell integrity (Grisham et al., 1990; de Mattos et al., 2015).

Evidence suggests that probiotics, mainly lactic acid bacteria (LAB), are promising candidates for the prevention and control of IBD. Animal model-derived colitis data indicate that specific LAB strains may be used to prevent and treat intestinal inflammation because they modulate inflammation and reduce histological damage (Scaldaferri and Fiocchi, 2007; Sheil et al., 2007; Floch, 2014). Moreover, probiotics can restore the balance of the resident microbiota (Shoaib et al., 2015).

The growing interest in the development of functional foods has prompted the search for new strains for probiotic applications. Thus, various fermented products have served as a source of LAB, which might help the development of health-promoting products (Todorov et al., 2008; Feng et al., 2015). The fermentation of cocoa beans (Theobroma cacao), the main raw material in the manufacture of chocolate, is known to produce these microorganisms;

Genetics and Molecular Research 15 (3): gmr.15038097 
many species of Lactobacillus, e.g., Lactobacillus fermentum, Lactobacillus plantarum, Lactobacillus cellobiosus, and Lactobacillus brevis, have been identified in the fermentation environment (Schwan and Wheals, 2004).

Our study aimed to access the probiotic potential of cocoa fermentation-derived LAB by testing their ability to reverse the inflammatory process in an experimental colitis model.

\section{MATERIAL AND METHODS}

\section{Study design}

Twenty-four rats were divided into four experimental groups of six animals each: two experimental groups and two control groups (positive control and standard group). The experimental groups and positive controls were subjected to intrarectal instillation of $10 \%$ acetic acid to induce colitis. The treatment was initiated by oral administration of probiotics to the experimental groups $24 \mathrm{~h}$ after the induction of intestinal inflammation. One of the experimental groups was treated with a mix of $L$. plantarum and L. fermentum strains (LAB pool); the second experimental group was treated only with $L$. fermentum (single strain). Each experimental group received $2 \mathrm{~mL}$ fermented milk drink/day containing probiotics $\left(10^{9} \mathrm{UFC} /\right.$ $\mathrm{mL}$ ) for 7 days. The positive control developed intestinal inflammation, but did not receive treatment. The standard control consisted of the untreated normal group, which did not develop inflammation. On day 8, the animals were sacrificed for blood collection and macroscopic and microscopic colon analysis.

\section{Animals}

Male Wistar rats (Rattus norvegicus; 8-12 weeks old; 200-250 g) were used as the experimental colitis models. The animals were accommodated in a room with controlled temperature and light and had free access to food and water. The rats were anesthetized with halothane and colitis was induced on day zero by intrarectal administration of $10 \%$ acetic acid solution ( $1 \mathrm{~mL} /$ animal) administered with a $3.5 \mathrm{~F}$ catheter inserted $2 \mathrm{~cm}$ proximal to the anus. After the experiments, the animals were sacrificed by an overdose of halothane and samples of blood and proximal colon were collected to investigate inflammation. The Local Animal Care and Use Committee approved all experimental protocols described in this study.

\section{Isolation and identification of microorganisms}

Cocoa beans $(100 \mathrm{~g})$ were collected from a fermentation box every $12 \mathrm{~h}$ for 5 days for the isolation of $\mathrm{LAB}$. They were suspended in saline $(0.85 \% \mathrm{NaCl})$ and processed in a Waring blender. Next, the pulp was serially diluted and plated on MRS agar (HiMedia, Mumbai, India). After growth at $37^{\circ} \mathrm{C}$ under anaerobic conditions $\left(5 \% \mathrm{CO}_{2}\right)$ for $24 \mathrm{~h}$, the isolates were tested for catalase activity and those that were catalase-negative were submitted to Gram staining. The Gram-positive and catalase-negative rods were re-isolated and maintained in MRS broth (HiMedia) with 25\% glycerol at $-20^{\circ} \mathrm{C}$ for further experiments. Bacteria were subjected to DNA extraction, polymerase chain reaction (PCR), and sequencing. The sequencing was carried out by a sequencing service provider, Ludwig Biotec Co. (Alvorada, RS, Brazil). Sequences were analyzed in silico and the isolates were identified according to similarity, with cut-off at similarity $>97 \%$.

Genetics and Molecular Research 15 (3): gmr.15038097 


\section{Extraction of genomic DNA}

Cultures that had been grown in MRS broth for $24 \mathrm{~h}$ were washed twice in 0.1 $\mathrm{M}$ phosphate-buffered saline, $\mathrm{pH} 7\left(1 \mathrm{M} \mathrm{K}_{2} \mathrm{HPO}_{4}, 1 \mathrm{M} \mathrm{KH}_{2} \mathrm{PO}_{4}\right)$, and after discarding the supernatant, the pellets were homogenized in lysis buffer $(10 \mathrm{mM}$ Tris, $\mathrm{pH} 7.4,10 \mathrm{mM} \mathrm{NaCl}$, $25 \mathrm{mM}$ ethylenediaminetetraacetic acid, $1 \%$ sodium dodecyl sulfate). Proteinase K (50 $\mu \mathrm{L} /$ $\mathrm{mL}$ ) was then added and the samples were incubated for $1 \mathrm{~h}$ at $42^{\circ} \mathrm{C}$. Thereafter, the samples were mixed with the same volume of phenol/chloroform/isoamyl alcohol (25:24:1) by gentle inversion for $10 \mathrm{~min}$. The mixture was centrifuged for $10 \mathrm{~min}$ at $14,000 \mathrm{~g}$ at $4{ }^{\circ} \mathrm{C}$, and the aqueous phase was transferred to a fresh tube where precipitation with sodium acetate $(3 \mathrm{M}$, $\mathrm{pH} 3.0$ ) and $100 \%$ cold ethanol occurred. This mixture was chilled to $-20^{\circ} \mathrm{C}$ for $2 \mathrm{~h}$ and then centrifuged at $4{ }^{\circ} \mathrm{C}$ and $14,000 \mathrm{~g}$ for $30 \mathrm{~min}$. The pellet was washed with $70 \%$ cold ethanol and re-suspended in sterile ultrapure water. The DNA concentration was verified by $1 \% \mathrm{w} / \mathrm{v}$ agarose gel electrophoresis.

\section{PCR}

Each DNA sample was subjected to amplification using the forward primer Lac1 (5'-AGCAGTAGGGAATCTTCCA-3') and the reverse primer Lac2 (5'-GATTYCACCGCTACACATG-3'). The $50 \mu \mathrm{L}$ mixture contained 25 pmol each primer, $0.2 \mathrm{mM}$ each dNTP, $1 \mathrm{X}$ buffer, $3.7 \mathrm{mM} \mathrm{MgCl}, 0.4 \mathrm{mg} / \mathrm{mL}$ bovine serum albumin, $2.85 \mathrm{U}$ Taq polymerase (Fermentas, ThermoFisher Scientific, Waltham, MA, USA), and 10 ng DNA. The amplification process comprised an initial denaturation step at $94^{\circ} \mathrm{C}$ for $2 \mathrm{~min} ; 35$ cycles of 1 min at $94^{\circ} \mathrm{C}, 2 \mathrm{~min}$ at $60^{\circ} \mathrm{C}$, and $1 \mathrm{~min}$ at $72^{\circ} \mathrm{C}$ and a final extension step at $72^{\circ} \mathrm{C}$ for $30 \mathrm{~min}$. The amplified DNA was examined by agarose gel electrophoresis.

\section{Sequencing}

The PCR fragments were sent for sequencing by Ludwig Biotech.

\section{Preparation of fermented solutions}

Ten strains of L. fermentum and L. plantarum were randomly chosen from all the cocoa fermentation collection time-points and were grown separately in MRS broth for $24 \mathrm{~h}$ at $37^{\circ} \mathrm{C}$. The cells were collected by centrifugation at $7000 \mathrm{~g}$ for $10 \mathrm{~min}\left(20^{\circ} \mathrm{C}\right)$, washed, and resuspended in saline $(\mathrm{NaCl} 0.85 \%)$ to $\mathrm{A}_{600 \mathrm{~nm}}=0.3\left(\mathrm{~A}_{600 \mathrm{~nm}}\right.$ is the absorbance, or optical density, of a sample measured at a wavelength of $600 \mathrm{~nm}$ ). Fermented milk drinks were prepared by dissolving skimmed milk powder in water $(1: 10)$, heating to $85^{\circ} \mathrm{C}$ for $5 \mathrm{~min}$, and immediately cooling to $42^{\circ} \mathrm{C}$ in an ice bath. The milk solutions were inoculated with bacteria diluted in saline. Fermentation was performed at $42^{\circ} \mathrm{C}$ until the samples reached $\mathrm{pH} 4.5$, and the formed clumps were broken up by shaking and cooling to $20^{\circ} \mathrm{C}$ in an ice bath. The LAB concentration was determined by plating serial dilutions on MRS agar and counting the colonies. When necessary, the cell number was adjusted to $10^{9} \mathrm{CFU} / \mathrm{mL}$. After adjustment of the cell titers, there was a random mixture of strains. We simultaneously prepared a fermented milk drink containing only one isolate of $L$. fermentum by following the same procedure described above. The suspensions were kept refrigerated at $2^{\circ}-8^{\circ} \mathrm{C}$.

Genetics and Molecular Research 15 (3): gmr.15038097 


\section{Leukocyte blood count}

Blood samples were diluted in Türk's solution (1:20) and counted using a Neubauer chamber and a light microscope at 400X magnification. For differential counts, 100 leukocytes were counted in blood smears that had been subjected to Wright's staining, and visualized by light microscopy at 400X magnification.

\section{Macroscopic and microscopic damage}

Immediately after euthanasia, the rat colons were removed and rinsed with saline. Intestinal damage was analyzed by observing macroscopic lesions, the presence of liquid feces, and edema. To assess microscopic damage, a segment of proximal colon was resected and fixed in 10\% formalin. After dehydration in an ascending series of alcohol and xylol, the samples were embedded in paraffin. Sections (7-mm thick) were stained with hematoxylin and eosin and examined by light microscopy at 100X and 400X.

\section{Analysis of cytokines and immunoglobulin A (IgA)}

Serum concentrations of interferon gamma (IFN- $\gamma$ ), tumor necrosis factor alpha (TNF- $\alpha$ ), interleukin-10 (IL-10), and IgA were measured using the enzyme-linked immunosorbent assay (ELISA). The experimental procedures were conducted according to the respective manufacturers' instructions (eBioscience rat IFN- $\gamma$ ELISA, San Diego, CA, USA; eBioscience rat TNF- $\alpha$ ELISA; RayBiotech IL-10 ELISA Kit, Norcross, GA, USA; Immunology Consultants Laboratory, Inc. rat IgA ELISA, Portland, OR, USA).

\section{Statistical analysis}

The difference between the experimental groups and controls was tested by analysis of variance (ANOVA) using the GraphPad Prism 3.0 software. All tests were performed in duplicate and the results represent the average of two experiments.

\section{RESULTS}

\section{Isolation and genetic identification}

Initially, samples of cocoa beans were collected every $12 \mathrm{~h}$ for counting and identification of LAB. During the five days of fermentation, 80 strains of catalase-negative, Gram-positive bacilli were isolated. The sequencing identified 68 isolates as L. fermentum and 12 as L. plantarum, using the Lac1/Lac2 primer pair.

\section{Total and differential leukocyte counts}

LAB pool treatment, at a dose of $10^{9} \mathrm{CFU} / \mathrm{mL}$, decreased the global and differential blood count of the leukocytes. The total number of leukocytes was significantly decreased in comparison with the positive control. However, treatment with the single strain displayed a tendency to increase the count of these cells compared with the normal control. The total 
leukocyte count also differed in the experimental groups, with a significant decrease in the LAB pool-treated group in relation to animals treated with the single strain (Figure 1A). The LAB pool induced a significant decrease of neutrophils and monocytes in comparison with the positive controls. Conversely, treatment with the single strain induced a high count of these cells compared with both the control groups, although the differences were not statistically significant (Figure 1B and 1C). The ratio of lymphocytes was higher in the group treated with the LAB pool and decreased in the group treated with the single strain-fermented drink (Figure 1D). There was no difference in eosinophil count in any of the experimental groups.

A

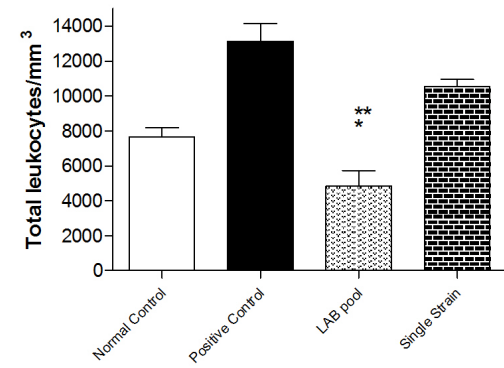

C

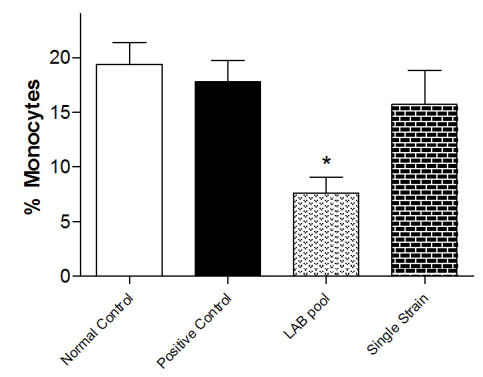

B

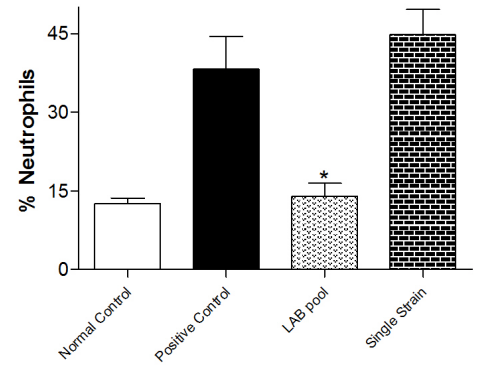

D

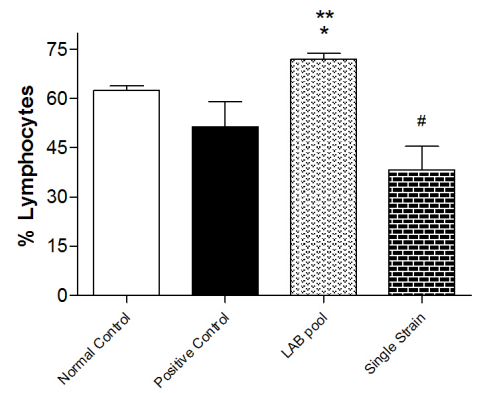

Figure 1. Total and differential leukocytes quantification. Animals that developed chemically induced colitis were treated with probiotics in fermented dairy solutions containing a mix of strains [lactic acid bacteria (LAB) pool] or an isolated strain (single strain) for 1 week. On the eighth day, the animals were euthanized to collect blood and colon samples. The positive control developed colitis, but was not treated. The normal control did not exhibit colon inflammation and was not treated with LAB. A. Blood leukocytes global count. *Significant decrease as compared to positive control; **significant decrease in relation to single strain group $(\mathrm{P}<0.05)$. B. Blood circulation neutrophils rate. ${ }^{*}$ Significant decrease in relation to positive control $(\mathrm{P}<0.05)$. C. Blood circulation monocytes rate. * Significant decrease as compared to positive control $(\mathrm{P}<0.05)$. D. Blood circulation lymphocytes rate. *Significant difference as compared to positive control $(\mathrm{P}<0.05)$;**significant difference as compared to single strain group $(\mathrm{P}<0.05)$; ${ }^{*}$ significant difference as compared to normal control $(\mathrm{P}<0.05)$.

\section{Serum levels of cytokines and IgA}

The experimental group that received the LAB pool $( \pm 50 \mathrm{pg} / \mathrm{mL})$ showed a significant decrease in serum IFN- $\gamma$ compared with the positive control $( \pm 175 \mathrm{pg} / \mathrm{mL})$, a reduction of approximately $90 \%$. In contrast, the single strain group $( \pm 380 \mathrm{pg} / \mathrm{mL})$ showed high levels of 
IFN- $\gamma$ (Figure 2A). There was increased IL-10 production in the LAB pool group $( \pm 1600 \mathrm{pg} /$ $\mathrm{mL})$, significantly different from the normal control $( \pm 600 \mathrm{pg} / \mathrm{mL})$, while for the single strain group it remained unchanged $( \pm 700 \mathrm{pg} / \mathrm{mL})$ (Figure $2 \mathrm{~B})$. The serum concentration of TNF- $\alpha$ was similar in all the groups tested (data not shown). The group treated with the LAB pool $( \pm 720 \mathrm{pg} / \mathrm{mL})$ presented IgA serum levels three times higher than in the positive control $( \pm 215$ $\mathrm{pg} / \mathrm{mL}$ ). Conversely, the group of rats treated with the single strain showed low IgA serum levels (Figure 2C).

A

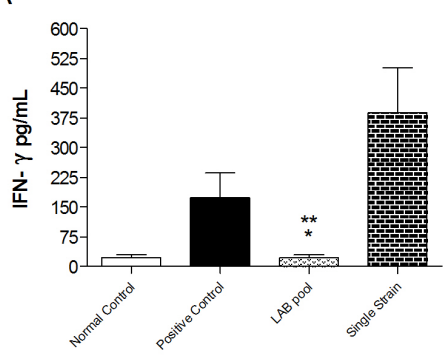

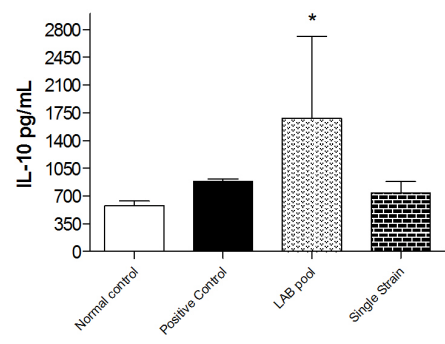

C

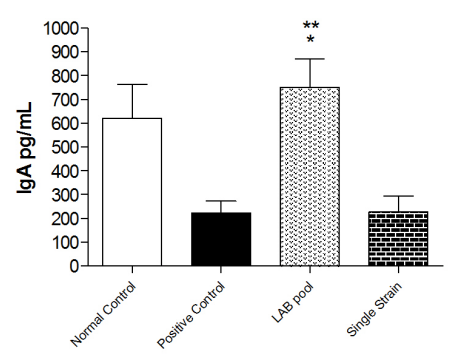

Figure 2. Cytokines and IgA serum concentration. Animals that developed chemically induced colitis were treated with probiotics in fermented dairy solutions containing a mix of strains [lactic acid bacteria (LAB) pool] or an isolated strain (single strain) for 1 week. On the eighth day, the animals were euthanized to collect blood and colon samples. The positive control developed colitis, but was not treated. The normal control did not exhibit colon inflammation and was not treated with LAB. A. Serum levels of IFN- $\gamma$. *Significant decrease as compared to positive control; **significant decrease as compared to single strain group $(\mathrm{P}<0.05)$. B. Serum levels of IL-10. *Significant difference as compared to normal control $(\mathrm{P}<0.05)$. C. Serum levels of IgA. *Significantly higher than positive control $(\mathrm{P}<0.05)$; **significantly higher than single strain group $(\mathrm{P}<0.05)$.

\section{Histological analysis}

Macroscopically, the colons of the positive control rats exhibited edema, hyperemia, and accumulation of feces. The rats treated with the LAB pool produced the best results, showing similarity to the standard controls without colitis. All rats treated with lactic acid solutions showed accumulation of intestinal gas (data not shown).

The histological analysis revealed that LAB pool treatment was efficient in promoting the recovery of colonic tissue. The untreated colitis group (positive control) presented colons with dense inflammatory infiltrate, with areas of necrosis, edema, and loss of tissue architecture (Figure 3A) compared with the normal control (Figure 3B). 


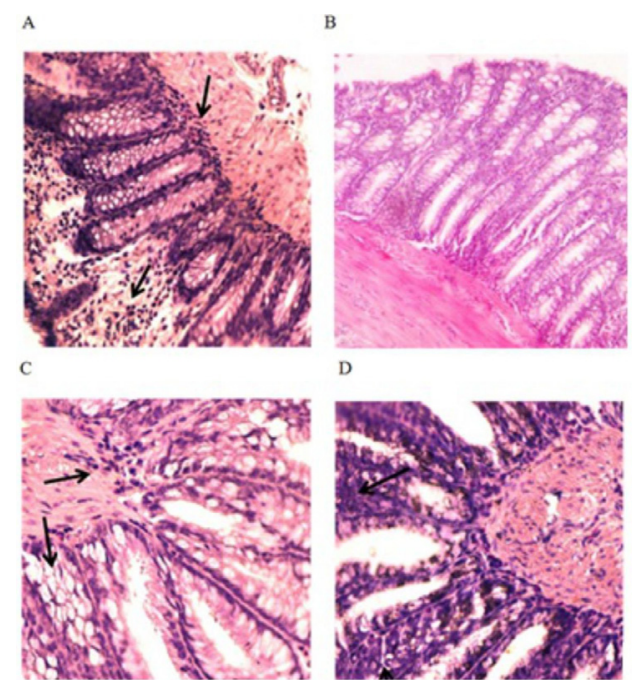

Figure 3. Histological analysis of colonic tissue. Animals that developed chemically induced colitis were treated with probiotics in fermented dairy solutions containing a mix of strains [lactic acid bacteria (LAB) pool] or an isolated strain (single strain) for 1 week. On the eighth day, the animals were euthanized to collect blood and colon samples. The positive control developed colitis, but was not treated. The normal control did not exhibit colon inflammation and was not treated with LAB. A. Positive control. The arrows indicate areas with accentuated inflammatory, neutrophil infiltration, and cryptic abscesses. B. Normal control. Normal appearance of the colonic mucosa. C. LAB pool group. The arrows show decreased number of inflammatory cells and glandular hypertrophy. D. Single strain group. The picture shows the inflamed tissue with disruption of the mucosa and areas of necrosis. (Hematoxylin and eosin, light microscope, 400X).

The LAB pool-treated group exhibited reduced inflammation and pronounced recovery (Figure 3C), with reduction of leukocyte infiltration, hypertrophy of glandular cells, and recovery of tissue structure. The single strain-treated group did not display signs of inflammation reduction, confirming the cytokine and IgA results (Figure 3D).

\section{DISCUSSION}

The microorganisms used as probiotics in humans for the treatment or prevention of diseases have generally been isolated from the feces of healthy individuals. However, recent studies have sought to investigate the probiotic potential of LAB isolated mainly from fermented products. Microorganisms from extra-intestinal sources have shown interesting properties, such as bacteriocin production, adherence to epithelial cells and mucus, and resistance to gastric pH and bile (Zoumpopoulou et al., 2008; Klayraung and Okonogi, 2009; Barbosa et al., 2014; Guerreiro et al., 2014; Tulumoğlu et al., 2014). In clinical studies, several species of Lactobacillus were able to reduce diarrhea and respiratory infections, and ameliorated symptoms of atopic dermatitis (Ciszek-Lenda et al., 2011; Nermes et al., 2011). Our results confirm this trend by presenting the anti-inflammatory action of LAB isolated from cocoa fermentation.

Several genera of LAB have been identified in cocoa fermentation, such as Leuconostoc, Enterococcus, Weissella, and especially Lactobacillus (Schwan and Wheals, 2004; Nielsen et al., 2007). Walter et al. (2001) demonstrated the specificity of Lac1/Lac2 
primers for the amplification of a fragment of the 16S rDNA of Lactobacillus. Using this primer set, the strains of Gram-positive and catalase-negative rods used in this study were identified as 68 isolates of $L$. fermentum and $12 \mathrm{~L}$. plantarum, according to the sequence. Despite the predominance of $L$. fermentum, the two species were isolated during all sampling times. The fact that the LAB were used in the pool of randomly selected strains meant that we could not correlate the immunological results with the points of fermentation at which each isolate was collected, since the physical and biochemical variations of the process did not allow us to select strains with particular characteristics.

To investigate the effect of LAB in an experimental colitis model, ten strains from cocoa fermentation (L. fermentum and L. plantarum) were randomly grouped (LAB pool), and this mix was used to treat rats suffering from chemically induced colitis. Another group of animals was treated only with $L$. fermentum (single strain). The treatment was started 1 day after the induction of intestinal inflammation, and lasted for 1 week.

Initially, we observed a reduction of the total number of blood leukocytes in the rats treated with the LAB pool. There were also marked decreases in the neutrophil and monocyte counts. The process of intestinal inflammation is associated with increased numbers of peripheral macrophages and polymorph nuclear leukocytes, which show an activated profile and increased survival, and are the main source of inflammatory cytokines (Nikolaus et al., 1998; Tanaka et al., 2008). Farooq et al. (2009) showed that the blockade of chemokine receptor CXCR2 in the neutrophils of mice with dextran sodium sulfate-induced colitis significantly reduced the number of neutrophils in the mucosa compared with the control, resulting in a reduction of the harmful effects on the tissue. Our findings suggest that the decrease of circulating leukocytes is related to the anti-inflammatory effect of LAB from cocoa. However, we could not determine if this result was due to the mechanism of action of these strains, or only reflected the reduction of inflammatory stimuli in the intestine.

In our study, treatment by LAB showed different effects on serum cytokines. The mixture of strains caused downregulation of IFN- $\gamma$ production, while inducing the antiinflammatory cytokine IL-10. However, the single strain-fermented drink was incapable of reducing the pro-inflammatory cytokine. Cytokines produced by circulating and infiltrated leukocytes are responsible for the exacerbation and perpetuation of the inflammatory process in IBD. In Crohn's disease, inflammation is mediated by Thl cells, which are induced by IL-12, leading to increased expression of pro-inflammatory cytokines such as IFN- $\gamma, \mathrm{TNF}-\alpha$, IL-2, IL-1, IL-6, and IL-8 (Waldner and Neurath, 2009). Conversely, IL-10 acts by modulating the inflammatory response and restoring tolerance to luminal antigens (Lammers et al., 2003). When we evaluated TNF- $\alpha$ serum levels, all groups presented similar concentrations. In the present study, this fact can be explained by the time of collection after 7 days of treatment. The TNF- $\alpha$ is produced in the early stages of inflammation and is quickly consumed in the blood. Moreover, many studies that evaluate this cytokine report its detection in the mucosa (Pavan et al., 2003; Peran et al., 2007). Similar to our findings, Zoumpopoulou et al. (2008), using the strain L. fermentum ACA-DC 179, observed high levels of IL-10, with the rate of IL-10/IL-12 significantly higher, suggesting the anti-inflammatory profile of this lineage.

Another immune aspect that has been investigated in studies of probiotic bacteria is IgA production. We observed an increased production of IgA antibody in the LAB pool group in comparison with the positive control. This group also showed the best results in histological analysis and levels of IFN- $\gamma$ and IL-10. IgA is the main immunoglobulin isotype secreted in mucosal surfaces and plays a central role in local immunity by creating a barrier

Genetics and Molecular Research 15 (3): gmr.15038097 
to pathogens. The activity of IgA may limit the contact of the normal microbiota with the epithelium, reducing the chances of activating a destructive inflammatory response (Suzuki et al., 2007). The increased serum and secretory levels of IgA are elevated after treatment with probiotics (Bakker-Zierikzee et al., 2006; Seifert et al., 2011). We believe that the probiotic effect of the LAB strains used in this study is related to $\operatorname{IgA}$ action, and acts by restoration of the acetic acid-damaged epithelial barrier. IgA prevents the invasion of the mucosa and limits the inflammatory stimulus, preventing tissue damage.

Acetic acid-induced colitis causes epithelial barrier dysfunction, loss of crypt of Lieberkühn architecture, and dense inflammatory infiltrate, resulting in the early stages of Crohn's disease and ulcerative colitis (Bouma and Strober, 2003; Rivera-Nieves et al., 2008). Although we observed the anti-inflammatory effects of the LAB pool in our rat model of acetic acid-induced colitis, when treating with Lactobacillus lactis, Steidler et al. (2000) found no effect on dextran sodium sulfate-induced inflammation in mice or spontaneous colitis developed in IL-10-deficient mice. In contrast, Dicksved et al. (2012), working with the same experimental model, found that Lactobacillus reuteri was able to maintain the barrier function of the mucosa, preventing microbial translocation, despite decreasing the mucus layer. The difference between these observations can probably be attributed to the use of different animal models and experimental settings. However, we believe that the use of non-isogenic experimental models is very important for the provision of data on the existence or otherwise of probiotic properties for developing a future product applicable to humans.

In this study, we aimed to assess the potential of LAB isolated from fermentation of cocoa for use as probiotics. We decided that an experimental design using pooled strains was the best way to test a higher number of microorganisms and minimize the use of animals. Interestingly, the group treated with a single strain showed different results, i.e., increased circulating leukocyte count, high IFN- $\gamma$ levels, and unrecovered histological aspects. For this reason, it is necessary to test the safety of probiotics for therapeutic use, since these microorganisms come into contact with the damaged mucosa. Lukic et al. (2013) tested the anti-inflammatory potential of the $L$. fermentum BGHI14 strain in an animal model of 2,4,6-trinitrobenzenesulfonic acid-induced colitis, and noted that even healthy animals showed an infiltrate of lymphocytes in the mucosa. However, there was no exacerbation of pathology in the colitis rats.

The different results found in this study in relation to multi- or single-strain probiotics can be explained by the uniqueness of each of the isolated strains, which were extracted at different fermentation times, and therefore showed different metabolic profiles. Our strains were isolated under different conditions of temperature, $\mathrm{pH}$, and oxygen availability-normal variables in the cocoa fermentation process. $\mathrm{LAB}$ of the same species isolated from a particular environment can present different probiotic characteristics. Furthermore, Timmerman et al. (2004), compared the functionality of multi-lineage probiotics and highlighted the superiority of these products for growth and reduced mortality in chickens, for the recovery of the intestinal microbial balance after antibiotic use, and for the treatment of infections caused by Salmonella spp and Escherichia coli O157: H7. However, detailed studies will clarify the role of each bacterium in the treatment of colitis.

Finally, we observed that Lactobacillus spp isolated from cocoa bean fermentation have probiotic potential and are able to modulate the chemically induced inflammatory process in rat models. A cocoa fermentation-derived combination of L. fermentum and L. plantarum can exert beneficial anti-inflammatory properties in an experimental colitis model. The results of our study reinforce the interest in using lactobacilli of non- human origin because the mix

Genetics and Molecular Research 15 (3): gmr.15038097 
of strains from cocoa fermentation stood out for its therapeutic effects in the experimental colitis model. The mix of strains modulated the serum cytokines and IgA, and reduced histological damage. The determination of functional activity is the starting point for the study of any probiotic microorganism. However, more detailed studies (e.g., with isogenic models and technological properties) are essential to confirm these findings. In our laboratory we are currently conducting studies to identify the mechanisms of action of these bacteria and their technological properties. We are also searching for new functional activities, even those relating to the bacterial substances involved in secondary metabolism. In addition, human clinical studies will enable the safe use of these strains.

\title{
Conflicts of interest
}

The authors declare no conflict of interest.

\section{ACKNOWLEDGMENTS}

\author{
We would like to thank CNPq funding agency.
}

\section{REFERENCES}

Bakker-Zierikzee AM, Tol EA, Kroes H, Alles MS, et al. (2006). Faecal SIgA secretion in infants fed on pre- or probiotic infant formula. Pediatr. Allergy Immunol. 17: 134-140.http://dx.doi.org/10.1111/j.1399-3038.2005.00370.x

Barbosa J, Borges S and Teixeira P (2014). Selection of potential probiotic Enterococcus faecium isolated from Portuguese fermented food. Int. J. Food Microbiol. 191: 144-148. http://dx.doi.org/10.1016/j.ijfoodmicro.2014.09.009

Bouma $\mathrm{G}$ and Strober W (2003). The immunological and genetic basis of inflammatory bowel disease. Nat. Rev. Immunol. 3: 521-533. http://dx.doi.org/10.1038/nri1132

Ciszek-Lenda M, Nowak B, Sróttek M, Gamian A, et al. (2011). Immunoregulatory potential of exopolysaccharide from Lactobacillus rhamnosus KL37: effects on the production of inflammatory mediators by mouse macrophages. Int. J. Exp. Pathol. 92: 382-391.http://dx.doi.org/10.1111/j.1365-2613.2011.00788.x

de Mattos BR, Garcia MP, Nogueira JB, Paiatto LN, et al. (2015). Inflammatory bowel disease: an overview of immune mechanisms and biological treatments. Mediators Inflamm. 2015: 493012. http://dx.doi.org/10.1155/2015/493012

Dicksved J, Schreiber O, Willing B, Petersson J, et al. (2012). Lactobacillus reuteri maintains a functional mucosal barrier during DSS treatment despite mucus layer dysfunction. PLoS One 7: e46399. http://dx.doi.org/10.1371/journal. pone.0046399

Farooq SM, Stillie R, Svensson M, Svanborg C, et al. (2009). Therapeutic effect of blocking CXCR2 on neutrophil recruitment and dextran sodium sulfate-induced colitis. J. Pharmacol. Exp. Ther. 329: 123-129. http://dx.doi. org/10.1124/jpet.108.145862

Feng J, Liu P, Yang X and Zhao X (2015). Screening of immunomodulatory and adhesive Lactobacillus with antagonistic activities against Salmonella from fermented vegetables. World J. Microbiol. Biotechnol. 31: 1947-1954.http:// dx.doi.org/10.1007/s11274-015-1939-6

Floch MH (2014). Recommendations for probiotic use in humans-a 2014 update. Pharmaceuticals (Basel) 7: 999-1007. http://dx.doi.org/10.3390/ph7100999

Grisham MB, Gaginella TS, von Ritter C, Tamai H, et al. (1990). Effects of neutrophil-derived oxidants on intestinal permeability, electrolyte transport, and epithelial cell viability. Inflammation 14: 531-542. http://dx.doi.org/10.1007/ BF00914274

Guerreiro J, Monteiro V, Ramos C, Franco BDGM, et al. (2014). Lactobacillus pentosus B231 isolated from a Portuguese PDO cheese: production and partial characterization of its bacteriocin. Probiotics Antimicrob. Proteins 6: 95-104.

Joint Food and Agriculture Organization (FAO)/World Health Organization (WHO) Working Group (2002). Guidelines for the evaluation of probiotics in food. London, Ontario, Canada. http://www.who.int/foodsafety/fs_management/ en/probiotic_guidelines.pdf. Accessed March 14, 2016.

Klayraung S and Okonogi S (2009). Antibacterial and antioxidant activities of acid and bile resistant strains of Lactobacillus fermentum isolated from Miang. Braz. J. Microbiol. 40: 757-766. http://dx.doi.org/10.1590/S1517$\underline{83822009000400005}$

Genetics and Molecular Research 15 (3): gmr.15038097 
Lammers KM, Brigidi P, Vitali B, Gionchetti P, et al. (2003). Immunomodulatory effects of probiotic bacteria DNA: IL-1 and IL-10 response in human peripheral blood mononuclear cells. FEMS Immunol. Med. Microbiol. 38: 165-172. http://dx.doi.org/10.1016/S0928-8244(03)00144-5

Lenoir-Wijnkoop I, Sanders ME, Cabana MD, Caglar E, et al. (2007). Probiotic and prebiotic influence beyond the intestinal tract. Nutr. Rev. 65: 469-489. http://dx.doi.org/10.1111/j.1753-4887.2007.tb00272.x

Lukic J, Strahinic I, Milenkovic M, Golic N, et al. (2013). Interaction of Lactobacillus fermentum BGHI14 with rat colonic mucosa: implications for colitis induction. Appl. Environ. Microbiol. 79: 5735-5744. http://dx.doi.org/10.1128/ AEM.01807-13

Nermes M, Kantele JM, Atosuo TJ, Salminen S, et al. (2011). Interaction of orally administered Lactobacillus rhamnosus GG with skin and gut microbiota and humoral immunity in infants with atopic dermatitis. Clin. Exp. Allergy 41: 370377.http://dx.doi.org/10.1111/j.1365-2222.2010.03657.x

Nielsen DS, Teniola OD, Ban-Koffi L, Owusu M, et al. (2007). The microbiology of Ghanaian cocoa fermentations analysed using culture-dependent and culture-independent methods. Int. J. Food Microbiol. 114: 168-186. http:// dx.doi.org/10.1016/j.ijfoodmicro.2006.09.010

Nikolaus S, Bauditz J, Gionchetti P, Witt C, et al. (1998). Increased secretion of pro-inflammatory cytokines by circulating polymorphonuclear neutrophils and regulation by interleukin 10 during intestinal inflammation. Gut 42: 470-476. http://dx.doi.org/10.1136/gut.42.4.470

Oelschlaeger TA (2010). Mechanisms of probiotic actions - A review. Int. J. Med. Microbiol. 300: 57-62. http://dx.doi. org/10.1016/j.ijmm.2009.08.005

Pavan S, Desreumaux P and Mercenier A (2003). Use of mouse models to evaluate the persistence, safety, and immune modulation capacities of lactic acid bacteria. Clin. Diagn. Lab. Immunol. 10: 696-701.

Peran L, Sierra S, Comalada M, Lara-Villoslada F, et al. (2007). A comparative study of the preventative effects exerted by two probiotics, Lactobacillus reuteri and Lactobacillus fermentum, in the trinitrobenzenesulfonic acid model of rat colitis. Br. J. Nutr. 97: 96-103. http://dx.doi.org/10.1017/S0007114507257770

Rivera-Nieves J, Gorfu G and Ley K (2008). Leukocyte adhesion molecules in animal models of inflammatory bowel disease. Inflamm. Bowel Dis. 14: 1715-1735. http://dx.doi.org/10.1002/ibd.20501

Saez-Lara MJ, Gomez-Llorente C, Plaza-Diaz J and Gil A (2015). The role of probiotic lactic acid bacteria and bifidobacteria in the prevention and treatment of inflammatory bowel disease and other related diseases: a systematic review of randomized human clinical trials. BioMed Res. Int. 2015: 505878. http://dx.doi.org/10.1155/2015/505878

Scaldaferri F and Fiocchi C (2007). Inflammatory bowel disease: progress and current concepts of etiopathogenesis. $J$. Dig. Dis. 8: 171-178. http://dx.doi.org/10.1111/j.1751-2980.2007.00310.x

Schwan RF and Wheals AE (2004). The microbiology of cocoa fermentation and its role in chocolate quality. Crit. Rev. Food Sci. Nutr. 44: 205-221. http://dx.doi.org/10.1080/10408690490464104

Seifert S, Fritz C, Carlini N, Barth SW, et al. (2011). Modulation of innate and adaptive immunity by the probiotic Bifidobacterium longum PCB133 in turkeys. Poult. Sci. 90: 2275-2280. http://dx.doi.org/10.3382/ps.2011-01560

Sheil B, Shanahan F and O’Mahony L (2007). Probiotic effects on inflammatory bowel disease. J. Nutr. 137 (Suppl 2): 819S-824S.

Shoaib A, Dachang W and Xin Y (2015). Determining the role of a probiotic in the restoration of intestinal microbial balance by molecular and cultural techniques. Genet. Mol. Res. 14: 1526-1537. http://dx.doi.org/10.4238/2015. February.20.8

Steidler L, Hans W, Schotte L, Neirynck S, et al. (2000). Treatment of murine colitis by Lactococcus lactis secreting interleukin-10. Science 289: 1352-1355. http://dx.doi.org/10.1126/science.289.5483.1352

Suzuki K, Ha SA, Tsuji M and Fagarasan S (2007). Intestinal IgA synthesis: a primitive form of adaptive immunity that regulates microbial communities in the gut. Semin. Immunol. 19: 127-135. http://dx.doi.org/10.1016/j. $\underline{\text { smim.2006.10.001 }}$

Tanaka T, Okanobu H, Yoshimi S, Murakami E, et al. (2008). In patients with ulcerative colitis, adsorptive depletion of granulocytes and monocytes impacts mucosal level of neutrophils and clinically is most effective in steroid naïve patients. Dig. Liver Dis. 40: 731-736. http://dx.doi.org/10.1016/j.dld.2008.02.012

Timmerman HM, Koning CJ, Mulder L, Rombouts FM, et al. (2004). Monostrain, multistrain and multispecies probiotics - A comparison of functionality and efficacy. Int. J. Food Microbiol. 96: 219-233. http://dx.doi.org/10.1016/j. ijfoodmicro.2004.05.012

Todorov SD, Botes M, Guigas C, Schillinger U, et al. (2008). Boza, a natural source of probiotic lactic acid bacteria. $J$. Appl. Microbiol. 104: 465-477.

Genetics and Molecular Research 15 (3): gmr.15038097 
Tulumoğlu Ş, Kaya Hİ and Şimşek Ö (2014). Probiotic characteristics of Lactobacillus fermentum strains isolated from tulum cheese. Anaerobe 30: 120-125.http://dx.doi.org/10.1016/j.anaerobe.2014.09.015

Waldner MJ and Neurath MF (2009). Novel cytokine-targeted therapies and intestinal inflammation. Curr. Opin. Pharmacol. 9: 702-707. http://dx.doi.org/10.1016/j.coph.2009.07.005

Walter J, Hertel C, Tannock GW, Lis CM, et al. (2001). Detection of Lactobacillus, Pediococcus, Leuconostoc, and Weissella species in human feces by using group-specific PCR primers and denaturing gradient gel electrophoresis. Appl. Environ. Microbiol. 67: 2578-2585.http://dx.doi.org/10.1128/AEM.67.6.2578-2585.2001

Zemljic M, Pejkovic B, Krajnc I and Lipovsek S (2014). Biological pathways involved in the development of inflammatory bowel disease. Wien. Klin. Wochenschr. 126: 626-633. http://dx.doi.org/10.1007/s00508-014-0592-7

Zoumpopoulou G, Foligne B, Christodoulou K, Grangette C, et al. (2008). Lactobacillus fermentum ACA-DC 179 displays probiotic potential in vitro and protects against trinitrobenzene sulfonic acid (TNBS)-induced colitis and Salmonella infection in murine models. Int. J. Food Microbiol. 121: 18-26. http://dx.doi.org/10.1016/j.ijfoodmicro.2007.10.013

Genetics and Molecular Research 15 (3): gmr.15038097 